\title{
Influence of turbulent boundary conditions on RANS simulations of pollutant dispersion in mechanically ventilated enclosures with transitional slot Reynolds number
}

The first author:

Shi-Jie Cao,

Email address: shijie.cao@mech.kuleuven.be

The second author, Corresponding author :

Johan Meyers,

Email address: johan.meyers@mech.kuleuven.be

\section{Address:}

Department of Mechanical Engineering, KU Leuven,

Celestijnenlaan 300A — bus 2421, B3001 Leuven, Belgium

tel: $+32(0) 16322511$

fax: +32 (0)16322985 


\section{Influence of turbulent boundary conditions on RANS}

\section{simulations of pollutant dispersion in mechanically}

\section{ventilated enclosures with transitional slot Reynolds}

\section{number}

Abstract We investigate the influence of turbulent inlet boundary conditions on indoor air-flow characteristics and pollutant dispersion in Reynolds-averaged Navier-Stokes (RANS) simulations of an indoor ventilated enclosure at a transitional slot Reynolds number. A benchmark ventilation case is considered - for comparison experimental PIV data are available. Two turbulence closure models are included in the study, i.e., a low-Reynolds-number $k-\varepsilon$ model, and the SST $k-\omega$ model. When looking at velocity fields, we find that the influence of turbulent length scales at the inlet boundary on the indoor flow field is small. The influence of turbulence intensity (ranging between $2 \%$ and $30 \%$ ) is considerably larger, in particular affecting the separation point of the inlet jet along the top wall. When further investigating the effect of turbulent conditions at the inlet on pollutant dispersion for a hypothetical indoor contaminant release case, we find that variations of inlet turbulent length scales lead to differences in pollutant concentration of up to $20 \%$. Variations due to changes in inlet turbulent intensity lead to differences up to a factor 2 . These findings strongly emphasize the importance of imposing realistic boundary conditions for turbulence models, refuting the common working hypothesis, often used in the indoor-ventilation literature, that varying these conditions has negligible impact on simulation results.

Key words: Mechanical ventilation, indoor air-flow, RANS simulation, PIV experiment 


\section{Introduction}

The essential function of building ventilation systems is to supply fresh air and to remove contaminants, providing a healthy and comfortable environment. The importance of indoor air-flow characteristics to control contaminant removal has been documented by many investigators [1-5]. For the design of ventilation systems, either numerical simulations or small-scale experiments are usually required to assure highly efficient and well-performing ventilation systems [6-8]. As a result of continuing developments in computer performance, numerical simulations, i.e., Computational Fluid Dynamics (CFD), are more and more used to facilitate ventilation design.

Numerical simulations of the indoor air-flow, mass, and heat exchange in ventilation systems have been carried out through different methods [9-11], either relying on large eddy simulations [12-14], Reynolds-averaged Navier-Stokes simulations (e.g. relying on eddy viscosity models [15], or Reynolds stress models (RSM) [16]), and even a few direct numerical simulations [17-18]. However, nowadays RANS models such as the RNG $k-\varepsilon$ or the SST $k-\omega$ model are most often used [2, 6-11], as other approaches require too much computational resources.

An important element for RANS simulations is the prescription of inlet boundary conditions, including the inlet velocity profile, geometry, location, etc., which are known to have a large impact on the ventilation performance [19-23]. Next to that, also turbulence intensities and length scales need to be given as a boundary condition for the RANS turbulence model. The sensitivity of indoor ventilation to inlet turbulence levels has been studied by Abdighanie et al. [24] and Joubert et al. [25], respectively using slot Reynolds numbers of 4895, and 5096. They investigated the effects of inlet turbulence intensities, and concluded that the flow field in the ventilated enclosure is insensitive to inlet turbulence levels. Joubert et al. [25] also studied the influence of inlet velocity profiles, and found that 


\section{Accepted Manuscript}

they do not greatly affect the average flow distribution inside the cavity, but do have a strong impact on turbulent quantities. Also Awbi [26] states that inlet turbulent intensities ranging between $4 \%$ and $37 \%$ do not affect the flow solution. Schalin and Nielsen [27] studied the impact of turbulence anisotropy near walls in ventilated indoor air-flow with RSM models, and pointed out that turbulent intensities of $0.1 \%$ and $4 \%$ at the inlet give the same results. Their study used a slot Reynolds number of 4700 .

The current manuscript is studying the influence of the turbulent inlet boundary conditions on RANS simulations at a transitional slot Reynolds number. Effects on both flow field and pollutant dispersion are investigated. Hence, we reevaluating the results found in [24-27], but we focus on a lower slot Reynolds number of 1500 (based on slot height). At these low Reynolds numbers, transitional effects near the inlet may play an important role. In that case turbulent boundary conditions may have a much larger effect, as they impact on the local transition to turbulence of the inlet jet.

Therefore, a ventilation benchmark case is considered for which we have also experimental flow data available. The Reynolds number at the inlet slot is relatively low (i.e. $R e_{s}=1500$ ), corresponding to the low velocities typically required for ventilation comfort in full scale applications. In the simulations, a pollutant source is also included, allowing us to look at predicted pollutant concentrations. A range of turbulent intensities $(5 \%-30 \%)$ at the inlet boundary is considered in combination with three possible turbulent length scales (i.e., either corresponding to $7 \%$ of the hydraulic diameter, to the size of upstream screen openings in the upstream flow conditioner of the experimental setup, or a third size in between).

The manuscript is further structured as follows. First, in Section 2, the governing equations used in the simulations are briefly reviewed. Next, the details of both the experimental set-up and the numerical set-up are described in Section 3. Subsequently, Section 4 presents a number of RANS simulations in which the effects of turbulent inlet 
Accepted Manuscript

boundary conditions are evaluated, and comparisons with the experiments are discussed. Finally, conclusions are presented in Section 5.

\section{Governing equations for indoor ventilation}

In the current study, a simple benchmark ventilation case is considered (both numerically, and experimentally) for an indoor environment (or 'room') with an in- and outlet and a source distribution of gaseous pollutants $S_{p}$ (see Figure 1 for a sketch). The volume of the room and inlet-vent area are $\Omega$, and $A$. The room conditions are isothermal, constant-density, with $\rho=\rho_{0}$ and steady state. At the inlet, clean air is is supplied with an average velocity $U_{0}$

We now present the normalized transport equations describing this system (a more detailed derivation is presented in Cao and Meyers [28]). To this end, a particular normalization is selected, i.e., the reference length $L=\Omega^{1 / 3}$, the reference velocity is $U_{0}$, and the reference density corresponds to $\rho_{0}$. For the concentration, the well-mixed pollutant concentration (the average mass fraction) $Y_{O}$ at the ventilation outlet is used as a reference. The mass-flux of air into the domain corresponds to $\dot{m}_{a}$, while the mass-flux of pollutant corresponds to $\dot{m}_{p}$, such that $Y_{o}=\dot{m}_{p} /\left(\dot{m}_{a}+\dot{m}_{p}\right)=1 /(1+\alpha)$, with $\alpha \equiv \dot{m}_{a} / \dot{m}_{p}$. Using this normalization, the non-dimensional Reynolds-averaged Navier-Stokes equations, using an eddy viscosity, and eddy diffusivity to model the Reynolds stresses, and fluxes respectively, are given by [28].

$$
\begin{aligned}
& \nabla^{*} \cdot\left(\tilde{\mathbf{u}}^{*}\right)=\frac{K}{\alpha} S_{p}^{*}, \\
& \nabla^{*} \cdot\left(\tilde{\mathbf{u}}^{*} \otimes \tilde{\mathbf{u}}^{*}\right)+\nabla^{*} \bar{p}^{*}-\frac{2}{\operatorname{Re}} \nabla^{*} \cdot\left(1+v_{t}^{*}\right)\left[S^{*}-\operatorname{tr}\left(S^{*}\right) I / 3\right]=0,
\end{aligned}
$$




$$
\nabla^{*} \cdot\left(\tilde{\mathbf{u}}^{*} \tilde{C}^{*}\right)-\frac{1}{\operatorname{Re} S c} \nabla^{*} \cdot\left(1+D_{t}^{*}\right) \nabla^{*} \tilde{C}^{*}=\left(1+\frac{K}{\alpha}\right) S_{p}^{*}
$$

where $\tilde{u}^{*}$ and $\tilde{C}^{*}$ are Reynolds averaged velocity and concentration, $K=A / L^{2}$ is a constant, and $S_{p}^{*}$ the normalized pollutant source term. Further $S^{*}$ the strain rate tensor, $R e$ is the Reynolds number, $S c$ the Schmidt number, and $v_{t}^{*}, D_{t}^{*}$ are the eddy viscosity and eddy diffusivity respectively. Further details and definitions can be found in Table.1.

Table 1. Summary of terms and expression used in the RANS equations

$$
\begin{aligned}
& L=\Omega^{1 / 3}, \quad \dot{m}_{a}=\rho_{0} U_{0} A, \quad \dot{m}_{p}=\iiint_{\Omega} S_{p}(\mathbf{x}) \mathrm{d} \mathbf{x}, \quad Y_{o}=\dot{m}_{p} /\left(\dot{m}_{a}+\dot{m}_{p}\right)=1 /(1+\alpha) \\
& S_{p}^{*}=S_{p} L^{3} / \dot{m}_{p}, S^{*}=\left[\nabla^{*} \tilde{\mathbf{u}}^{*}+\left(\nabla^{*} \tilde{\mathbf{u}}^{*}\right)^{T}\right] / 2, R e=U_{0} L / v_{0}, v_{0}=\mu_{0} / \rho_{0}, \\
& S c=v_{0} / D=0.8, \quad v_{t}^{*}=v_{t} / v_{0}, \quad D_{t}^{*}=D_{t} / D, \quad D_{t}=v_{t} / S c_{t}, \quad S c_{t}=0.9
\end{aligned}
$$

In the current study we use either the low-Reynolds number $k-\varepsilon$ model of Chang et al. [29], or a SST $k-\omega$ model [30] to model the eddy viscosity, i.e. the turbulent viscosity is respectively approximated with $v_{t} \sim k^{2} / \varepsilon$, and $v_{t} \sim k / \omega$. Further details on these models are found in [29] and [30].

Remark that many studies recommend the RNG k- $\varepsilon$ model for ventilation applications, with predictions that compare well to experimental data [4,6-7]. However, in the current study, we do not include this model, as it introduces substantial modeling errors in the inlet geometry of our set-up (as further briefly explained in Section 4.3). Furthermore, we believe that trends observed for both low-Reynolds models that are included in the current work (as further discussed in next section) sufficiently demonstrate the need to better choose turbulent inlet conditions for ventilation simulations with transitional inlet-slot Reynolds numbers. 


\section{Experimental and numerical set-up of benchmark case}

\subsection{Experimental set-up}

In the current study, we use a set of experimental PIV measurements as reference data. The measurements were performed by Twan van Hooff and Bert Blocken (TUe) similar to those presented in [31,32], but with inlet-slot Reynolds number of 1500 (van Hooff \& Blocken, private communication). In the current section, we briefly review some details of this experimental set-up, as it dictates the selection of our computational domain, etc.

A reduced-scale model $(1: 6.67)$ of a cubical indoor enclosure [31] was adopted to perform flow visualizations and PIV measurements (see Figure 2). The setup is composed of a water column to drive the flow, a flow conditioning section, a cubic test section and an overflow. The conditioning section consists of a honeycomb, three screens and a contraction in order to obtain a uniform water flow at the inlet and to lower the turbulence level. The test section has size $0.3 \times 0.3 \times 0.3 \mathrm{~m} 3(\mathrm{~L}=0.3 \mathrm{~m})$, with a slot inlet width $(\mathrm{w})$ of $0.3 \mathrm{~m}(\mathrm{w} / \mathrm{L}=1)$, and slot height $h / L=0.1$. The height of the outlet was fixed at outlet of $h / L=0.0167$.

A 2D PIV system is used, consisting of a Nd:Yag $(532 \mathrm{~nm})$ double-cavity laser $(2 \times 200$ $\mathrm{mJ}$, repetition rate $<10 \mathrm{~Hz}$ ) used for illuminating the field view, one CCD (Charge Coupled Device) and a camera $(1376 \times 1040$ pixel resolution, max. 10 frames/s) for capturing images. The laser was mounted on a translation stage and was positioned above the cubic test section to create a laser sheet in the vertical center plane of the cube. The CCD camera was positioned perpendicular to the laser sheet plane (cf. Figure 3). More details on the experimental procedure, seeding, etc. can be found in [32].

\subsection{Numerical set-up}

In the current study, a series of RANS simulations are performed for two different configurations of the same ventilated enclosure, which corresponds with the experimental 


\section{Accepted Manuscript}

set-up available at Eindhoven University of Technology shown in Figure 2. The first configuration, on which we focus most, consists of the ventilated enclosure in which we locate the inlet boundary condition at the inlet slot of the room (cf. Figure $4 \mathrm{a}$ for a detail of geometry and grid). A second geometry (cf. Figure 4b) includes the upstream flow contraction, and places inlet boundary conditions just downstream of the honeycombs and screens in the experimental flow-conditioning unit.

At the inlet boundary, a uniform velocity profile is given, corresponding to a slot-Reynolds number $\operatorname{Re}_{s}$ (defined using $U_{0}$, and the inlet-slot height $0.1 L$ ) of 1500 (for the current case, this corresponds to $R e=15000$ as defined in $\S 2$ ). Next to that, a range of turbulence intensities (between 2\% and 30\%), and three different turbulent length scales are considered for the inlet boundary condition of the turbulence model. The first length scale corresponds to $7 \%$ of the hydraulic diameter of the inlet slot (i.e. $L_{t}=1 \times 10^{-2}$ ), often used as a rule of thumb in commerical CFD software, and related to the value which may be expected in fully developed pipe flow or channel flow $[26,33]$. The second value, i.e., $L_{t}=1 \times 10^{-4}$ corresponds to the mesh-opening size in the upstream screens of the experimental set-up. A third value of $L_{t}=1 \times 10^{-3}$ is selected ad hoc in between the first two values.

The computational mesh is block structured (cf. Figure $4 \mathrm{~b}$ containing a total of 1254400 cells for the case with contraction (i.e. $74 \times 40 \times 80$ cells in the inlet block, $80 \times 152 \times 80$ in the main block, and $20 \times 28 \times 80$ cells in the outlet). The grid is stretched near the wall, and the first grid-point is typically located at a distance of $0.5 \times 10^{-3} L$ from the wall. For the current Reynolds number of 1500, we verified that this ensures a distance from the wall, using inner units, which remains well below $y^{+}=5$, such that the near-wall region is sufficiently resolved to justify the use of the low-Reynolds number $k-\varepsilon$ model and the SST $k-\omega$ model. A grid refinement study is also performed, with a finer grid using a total of 4140000 cells (compared to 1254400 for the baseline case). We find that the baseline case is sufficiently 
Accepted Manuscript

resolved, with differences of velocity and turbulent kinetic energy between the two grid cases remaining below 3 percent (results are not further shown here).

In order to study the effect of turbulent inlet conditions on effective ventilation efficiency, we also consider the dispersion of pollutants in the simulations. To this end, a case with a surface source of pollutants inside the ventilated enclosure is considered as shown in Figure 5. For sake of simplicity, we select the source to be uniformly distributed over this surface. The pollutant concentration is taken as a passive scalar and independent of flow field.

All simulations were performed with the commercial software package ANSYS Fluent. The incompressible pressure-based segregated solver was selected, using the default SIMPLE algorithm and a second-order upwind scheme for the convective terms. Solutions are iteratively converged until the sum of absolute normalized residuals of all cells in the simulation domain remain below an upper threshold of $10^{-5}$ the different equations. Simulations are performed on a high-performance computing system at the Flemish supercomputing center, containing Xeon 5650 nodes with 8 cores each. Nodes are interconnected with a dual-rail quaddata-rate infiniband network. Simulations are typically performed on 16 cores, roughly requiring $3.5 \mathrm{~h}$ per simulation.

\section{Results and Discussion}

In the current section, the impact of turbulent inlet conditions on the predicted indoor ventilation is studied. We recall that we focus on a case with a transitional slot-Reynolds number, i.e. $R e_{s}=1500$ for all cases. In Section 4.1, a comparison of flow predictions is presented, including a comparison with experimental data. Subsequently, in Section 4.2, we concentrate on pullutant dispersion predictions for the different cases. Finally, aspects related to the inclusion of upstream flow geometry are discussed in Section 4.3. 


\subsection{The influence of turbulent boundary conditions on the flow-field}

\section{predictions}

The focus in the current section is on the effect of turbulent boundary conditions on velocity and pollutant predictions for the first simulation geometry, i.e. excluding the representation of the inlet contraction. This corresponds to various practical modeling situations, in which the placement of boundary conditions at the room boundary are desirable (e.g., for reasons of computational cost, possibly complex upstream geometrical configurations, etc.).

First of all, in Figure 6 the effect of the turbulent length scale is investigated while keeping the turbulent intensity constant at a level of $2.5 \%$, in correspondance to the value identified in the experiments (note that during the PIV measurements, 360 uncorrelated samples were acquired for averaging [32], this leads to relative errors on the statistical averages of approx 5\%). In Figure 6, three different values are used for the length scale, as explained in Section 3.2. The turbulence model employed is the low Reynolds number $k-\varepsilon$ model of Chang et al. [29].

When looking at results in Figure 6, it is appreciated that the effect of the length scale on the velocity profiles measured along three vertical lines in the indoor enclosure is negligible. Moreover, all three simulations results display a location of the inlet jet which is too low when compared to experiments.

Further investigating the turbulent kinetic energy $k$ for the three different simulations (Figure 6, bottom row), we find that some influence is visible in the inlet-jet region. Close to the inlet $(\mathrm{x}=0.2 \mathrm{~L})$ the case with the lowest length scale yields the lowest level of turbulent kinetic energy, associated with a high level of turbulent dissipation (being inversely proportional to the length scale). Looking further downstream, these trends reverse and become less intuitive, now the case with the highest inlet-length scale has the lowest turbulent kinetic energy as a result of the streamwise evolution of turbulent dissipation along the the 
inlet jet. Though these differences do not significantly affect the mean-flow solution, a larger difference in pollution dispersion behavior may result, as further addressed in Section 4.2.

We now turn to an evaluation of the effect of changing the inlet turbulent intensity. Since the influence of the length scales on flow velocity field has negligible effects, we keep the turbulent length scale constant at a value of $\mathrm{L}_{\mathrm{t}}=1 \times 10^{-2}$, (i.e. obtained using the standard rule-of-thumb value of $7 \%$ of the inlet-slot hydraulic diameter - cf. also Section 3.2). As before, we do not include the inlet contraction in the model, but place the boundary condition at the room inlet. A comparison of stream-wise velocity profiles is shown in Figure 7 along three different lines in the domain, i.e. $(\mathrm{x}, \mathrm{z})=(0.2,0.5) \mathrm{L},(0.5,0.5) \mathrm{L},(0.8,0.5) \mathrm{L}$. Results using both the low-Re $k-\varepsilon$ and SST $k-\omega$ model are shown (Figure 7 top, and bottom respectivelly), and inlet turbulent intensities are varied between 5\%-30\% (with 5\% as increament), which is based on the effective range (4\%-37\%) mostly encountered in the practical ventilation applications [26].

For both the low-Re k- $\varepsilon$ and SST $k-\omega$ models, we find in Figure 7 that the effect of inlet turbulence intensity on velocity profiles near the inlet is relativelly small. However, when further looking at the downstream evolution of the streamwise velocity, larger disparities are observed, in particular in the inlet-jet region. First looking at the results from the $k-\varepsilon$ model, we find that the vertical location of the inlet-jet center shifts up with increasing inlet turbulent intensity. The best fit with experiments is found for an inlet-intensity of $15 \%$, which is considerably higher than the effective inlet intensity of $2.5 \%$ measured in the experiments. Also for the SST $k$ - $\omega$ model in Figure $7(\mathrm{~d}, \mathrm{e}, \mathrm{f})$, the same trends are visible. However, it is appreciated that velocity results are a lot less sensitive to changes in the turbulent intensity; in particular for inlet intensities from $15 \%$ to $30 \%$, results closely collapse.

To further investigate the behavior of the inlet-jet, and the resulting recirculation of air-flow in the indoor enclosure, we display in Figure 8 streamlines and (in color) the 
Accepted Manuscript

magnitude of the velocity for different inlet intensities. The model is a low-Re $k-\varepsilon$ model, and the turbulent length scale at the inlet corresponds to $L_{t}=1 \times 10^{-2}$. For comparison, experimental results obtained using PIV are also shown in Figure 8(g). From Figure 8, it is appreciated that the separation point of the jet from the top wall shifts downstream along that wall for increasing turbulent intensity at the inlet. As a result, also the internal recirculation zone changes its shape and magnitude, with more recirculated mass when turbulent intensities increase.

Finally, for the same case, an increase of turbulent intensity at the inlet also leads to an increased turbulent intensity in the rest of the domain, as shown in Figure 9. The higher levels of turbulent kinetic energy in the jet region explain the downstream shift of the jet separation. Next to that, higher levels of predicted turbulent kinetic energy also affect predictions of pollutant dissipation in indoor environments, as further addressed in next section.

\subsection{The influence of turbulent boundary conditions on predicted indoor concentration peaks}

We now turn to an evaluation of the effect of turbulent inlet conditions on indoor pollutant dispersion. To this end, we construct a test case, which consists of the same indoor environment as before, but extended with a pollutant source on a horizontal surface at a height of $y=0.3 \mathrm{~L}$ (cf. Figure 4 for a detail).

First of all, we investigate the effect of the inlet turbulent kinetic energy, keeping the inlet length scale at $L_{t}=1 \times 10^{-2}$. In Figure 10, concentration contour plots are shown for the different cases (at xy-plane $\mathrm{z}=0.5 \mathrm{~L}$ ) for different inlet turbulent intensities, and using the low-Re $k-\varepsilon$ model. It is clearly appreciated that the level of the turbulent kinetic energy at the inlet strongly influences the overall level of the pollutant concentration in the domain. The higher the inlet intensity, the lower the overall concentration level. This is partly a result of 
shifting indoor recirculation patterns, with more recirculation at higher intensities (cf. Figure 8 and discussion in Section 4.1), but apart from that, higher inlet intensities lead to higher Reynolds stresses and turbulent transport. This is further seen in Figure 11, where the eddy viscosity is shown for the different cases. Higher inlet turbulence intensities lead to higher eddy viscosities and eddy diffusivities. Hence, pollutant transport by turbulent interactions becomes more effective, in particular in the center of the primary recirculation zone, where mean flow velocities are relatively low, and pollutant concentrations tend to be higher.

In order to further quantify the effect of changing turbulent inlet conditions, we display in Figure 12 the locally averaged peak concentration of the different simulations as function of the turbulent intensity at the inlet, for three different length scales. Note that the concentration is normalized with the well-mixed concentration, which is on average leaving the enclosure (cf. section 2). Moreover, since looking at peak concentration itself is mathematically not always meaningful (e.g. pollutant point sources locally lead to infinite concentration levels), we instead look at the concentration levels which are locally averaged over a volume $(0.01 L)^{3}[28]$.

In Figure 12, it is observed that turbulent inlet conditions have a large impact on pollutant concentrations in indoor environments, in particular for the transitional slot Reynolds number considered in the current study. First of all, even though turbulent length scales do not have a significant direct impact on the mean flow field, its indirect impact on diffusion (via different turbulent intensities in the domain, cf. Figure 6) is considerable, e.g. up to $20 \%$ at an inlet turbulence intensity of $30 \%$. The effect of turbulent intensity itself is an order of magnitude higher, with a factor of 2 on local peak concentration between inlet intensities of 5\% and 30\% respectively. Note that this factor 2 in magnitude is also observed in Figure 10, and may be largely related to differences in eddy viscosity (cf. discussion above, and Figure 11). Finally, it should be remarked that these results are specific to the case 
Accepted Manuscript

selected in the current study. They highlight the importance of turbulent parameters for prediction of pollutant dispersion. However dependent on the air-flow pattern, and pollutant source location, the magnitude of the differences may change.

\subsection{Effect of upstream inlet geometry}

The current ventilation case corresponds to an experimental set-up which contains an inlet flow-conditioning section. In section 4.1 and 4.2, we investigated the effect of turbulent inlet conditions on results for simulations where the inlet-boundary condition was placed at the room inlet, ommitting the upstream flow contraction. Such an approach is common practice, as the upstream geometry may be too complex, or even not sufficiently well known to properly represent in many ventilation applications. In the current section, we compare such a pragmatic approach (i.e. results from previous sections) with simulations where the upstream geometry is included in the model.

For comparison with data from previous sections, we focus on the case with a turbulent intensity at the room inlet of $2.5 \%$, corresponding to the experimentally measured value. For simulations with upstream geometry, we choose a tubulent length scales at the upstream inlet that matches the mesh opening size of the screens in the upstream flow conditioner. However, since we do not know the turbulence intensity at that location, we have to iterativelly adapt the turbulent intensity such that the intensity at the room inlet corresponds to the experimental level. Results are shown in Figure 13, where the evolution of turbulent length scale, turbulent intensity, and turbulent viscosity are shown along the center line of the inlet contraction, and the downstream inlet jet. It is appreciated from this figure, that the turbulence intensities for both models reach a level of about $2.5 \%$ at the room inlet (i.e. at location $x / L=0$ ).

In Figure 14, results are shown comparing simulations with and without inlet contraction, both for the low-Re $k-\varepsilon$ and SST $k-\omega$ models. At the top of the figure, velocity profiles are shown, for which we find that results closely match. Consequently, the effect of 
Accepted Manuscript

upstream geometry does not play a decisive role on predicted velocity profiles provided velocities and turbulent intensities at the room inlet are correctly matched. When looking at the bottom part of Figure 14, it is observed that both models predict differences in turbulence intensities in the jet region of the flow, while other regions are less affected. A possible cause for this may be related to small differences in the shape of the inlet velocity profiles [25] (i.e. the inlet profile is uniform for the case without contraction, while a thin boundary layer exist for the case with contraction). Obviously, these differences in turbulent intensities may have an impact when pollutant dispersion is considered (as discussed in Section 3.2).

Finally, often the RNG k- $\varepsilon$ model is used in ventilation simulations [6-11]. However, for the case with inlet contraction, we found some of the modeling assumptions as implemented in ANSYS to be problematic. For simulation cases that are wall resolved, the RNG model is combined with a one-equation Wolfshtein model [35] in the viscous sublayer close to the wall. The demarcation between both models is determined using a wall-distance based turbulent Reynolds number, i.e., when $R e_{y}=y(k)^{1 / 2} / v<200$, the Wolfshtein model is employed [36]. Because of the low slot-Reynolds number in the current study, $R e_{y}<200$ anywhere in the inlet geometry. This leads to incorrect behavior of the free-stream turbulence (coming from the upstream screens) - physically it is expected to decay, while the Wolfshtein model predicts an increase along the contraction. Also inside the domain, the relative low turbulent Reynolds numbers in our current case, leads to near-wall regions where the one-equation Wolfshtein model is used up to $\mathrm{y}=0.12 \mathrm{~L}$. For this reason, we decided not to include ANSYS' RNG k- $\varepsilon$ model in the current study.

\section{Conclusions}

In the current study, we performed a series of RANS simulations to investigate the influences of turbulent inlet boundary conditions, i.e. turbulent intensity, and inflow turbulent length 
Accepted Manuscript

scales on predictions of velocity fields and contaminant distributions in indoor ventilation systems. A benchmark ventilation case was used for which experimental PIV data were also available.

In recent literature and ventilation practice [24-27], a common working hypothesis was that boundary conditions related to turbulence intensity and length scales do not have a signficant impact on indoor ventilation predictions. In the current study, we reevaluated these results for a lower (transitional) Reynolds number, at which effects of turbulent boundary conditions may play a more dominant role. Results in the current work indicate that inlet boundary conditions for turbulent quantities can have an important impact on predictions. When looking only at velocity fields, mainly the impact the turbulent intensity was of note, while effects of lengths scale were negligble. However when pollutant dispersion is also considered, the impact of turbulent quantities on indoor concentration may lead to differences in prediction of up to a factor 2 .

The conclusions in the current study are based on an evaluation of the SST k- $\omega$ model [30], and the low Reynolds $\mathrm{k}-\varepsilon$ of Chang et al. [29]. In these models, the level of turbulence intensities at the inlet had an impact on the predicted separation of the wall jet, while both turbulent intensity and length scales affect pollutant dispersion. Obviously, such observations need to be verified in the future for other type of RANS models, i.e., other eddy viscosity models, or Reynold-stress models.

Nowadays, trends in ventilation move towards lower ventilation rates and lower inlet-slot Reynolds numbers $[8,32]$. As a result CFD simulations become more challenging: one of the major difficulties identified in this context is, e.g., the accurate geometrical representation of the supply openings [36]. The current study further corroborates the importance of correct turbulence quantities at inlets for a simple benchmark geometry. To substantiate this for real-life applications, an important step in future research is the 
Accepted Manuscript

evaluation of these trends for more complex geometries. Moreover, for many applications aspects of mixed convection, e.g., in the presence of heat sources, may need to be also further taken into account.

\section{Acknowledgements}

The authors wish to thank Twan van Hooff and Bert Blocken (TUe) for providing their experimental results, which were supported by the Laboratory of the Unit Building Physics and Services (BPS) at Eindhoven University of Technology and the Laboratory of Building Physics at the KU Leuven. The authors also thank Twan van Hooff for useful feedback on the current manuscript. The authors further acknowledge financial support by the Flemish Science Foundation (FWO) under grant number G.0435.08. Simulations were performed on the computing infrastructure of the VSC - Flemish Supercomputer Center, funded by the Hercules Foundation and the Flemish Government.

\section{References}

[1] Chung K-C and Hsu S-P. Effect of ventilation pattern on room air and contaminant distribution. Building and Environment, 2001;36 (9): 989 - 998. ISSN 0360-1323.

[2] Norton T, Sun D-W, Grant J, Fallon R, and Dodd V. Applications of computational fluid dynamics (cfd) in the modelling and design of ventilation systems in the agricultural industry: A review. Bioresource Technology, 2007;98(12):2386-2414.

[3] Thatcher TL, Wilson DJ, Wood EE, Craig MJ, and Sextro RG. Pollutant dispersion in a large indoor space: Part 1-scaled experiments using a water-filled model with occupants and furniture. Indoor Air, 2004;14 (4): 258-271.

[4] Posner J.D , Buchanan, C.R, Dunn-Rankin D. Measurement and prediction of indoor air flow in a model room. Energy and Buildings, 2003; 35(5): pp. 515 - 526

[5] Hayashi T, Ishizu Y, Kato S, Murakami S. CFD analysis on characteristics of 
Accepted Manuscript

contaminated indoor air ventilation and its application in the evaluation of the effects of contaminant inhalation by a human occupant. Building and Environment, 2002; 37(3): pp. $219-230$

[6] Zhai Z, Zhang Z, Zhang W, Chen Q, Evaluation of various turbulence models in predicting airflow and turbulence in enclosed environments by CFD: Part 1 - Summary of prevalent turbulence models, HVAC\&R Research, 2007;13(6):853-870.

[7] Zhang Z, Zhang W, Zhai Z, and Chen Q. Evaluation of various turbulence models in predicting airflow and turbulence in enclosed environments by CFD: Part 2 - Comparison with experimental data from literature, HVAC\&R Research, 2007;13(6):871-886.

[8] Wang M and Chen Q. Assessment of various turbulence models for transitional flows in enclosed environment, HVAC\&R Research, 2009; 15(6):1099-1119.

[9] Chen Q. Ventilation performance prediction for buildings: A method overview and recent applications. Building and Environment, 2009;44 (4): 848 - 858. ISSN 0360-1323.

[10] Chen Q. Comparison of different k- $\varepsilon$ models for indoor air flow computations. Numerical Heat Transfer, Part B: Fundamentals, 1995;28 (3): 353-369.

[11] Gao N, Niu J, He Q, Zhu T, Wu J. Using RANS turbulence models and Lagrangian approach to predict particle deposition in turbulent channel flows, Building and Environment, 2012;48(0) Pages 206-214.

[12] Davidson $L$ and Nielsen P. Large eddy simulation of the flow in a three-dimensional ventilated room. In S. e. Murakami, editor, ROOMVENT '96 : Proceedings of the 5th International Conference on Air Distribution in Rooms, Yokohama, Japan, July 17-19, 1996; volume 2, pages 161-168.

[13] Wang M and Chen QY. On a hybrid rans/les approach for indoor airflow modeling (rp-1271). HVAC\&R Research, 2010;16 (6): 731-747.

[14] Zhang W and Chen Q. Large eddy simulation of indoor airflow with a filtered 
Accepted Manuscript

dynamic subgrid scale model. International Journal of Heat and Mass Transfer, 2000;43 (17): $3219-3231$.

[15] Moureh J and Flick D. Wall air-jet characteristics and airflow patterns within a slot ventilated enclosure. International Journal of Thermal Sciences, 2003;42 (7): 703 - 711.

[16] Moureh J and Flick D. Airflow characteristics within a slot-ventilated enclosure. International Journal of Heat and Fluid Flow, 2005;26(1):12-24.

[17] Shishkina O, Shishkin A, and Wagner C. Simulation of turbulent thermal convection in complicated domains. J. Comput. Appl. Math., 2009;226 (2): 336-344.

[18] Wagner C, Shishkin A, and Shishkina O. The use of direct numerical simulations for solving industrial flow problems. In H. Kuerten, B. Geurts, V. Armenio, and J. Frohlich, editors, Direct and Large-Eddy Simulation VIII, volume 15 of ERCOFTAC Series, pages 397-404. Netherlands: Springer; 2011.

[19] Feigley CE, Bennett JS, Khan J, and Lee E. Performance of deterministic workplace exposure assessment models for various contaminant source, air inlet, and exhaust locations. AIHA Journal, 2002;63 (4): 402-412.

[20] Khan J, Feigley C, Lee E, Ahmed M, and Tamanna S. Effects of inlet and exhaust locations and emitted gas density on indoor air contaminant concentrations. Building and Environment, 2006;41 (7): $851-863$.

[21] Lee E, Khan JA, Feigley CE, Ahmed MR, and Hussey JR. An investigation of air inlet types in mixing ventilation. Building and Environment, 2007;42(3):1089-1098. ISSN 0360-1323.

[22] Susin RM, Lindner GA, Mariani VC, and Mendonca KC. Evaluating the influence of the width of inlet slot on the prediction of indoor airflow: Comparison with experimental data. Building and Environment, 2009;44 (5): 971 - 986.

[23] Chen Q, and Srebric J. Simplified diffuser boundary conditions for numerical room 
Accepted Manuscript

airflow models," ASHRAE RP-1009, 2001;page:181.

[24] Abdilghanie AM, Collins LR , and Caughey DA. Comparison of turbulence modeling strategies for indoor flows. Journal of Fluids Engineering, 2009;131 (5).

[25] Joubert P, Sandu A, Beghein C, and Allard F. Numerical study of the influence of inlet boundary conditions on the air movement in a ventilated enclosure. In Proceedings of the Roomvent,Yokohama, Japan, 1996; volume 1, page 235-42.

[26] Awbi H. Ventilation of Buildings. 2nd edition. London and NewYork: Taylor and Francis (E\&FN Spon); 2003.

[27] Schalin A and Nielsen PV. Impact of turbulence anisotropy near walls in room airflow. Indoor Air, 2004;14 (3): 159-168.

[28] Cao S-J and Meyers J. On the construction and use of linear low-dimensional ventilation models. Indoor Air, 2012;pages no-no; doi: 10.1111/j.1600-0668.2012.00771.x.

[29] Chang KC, Hsieh WD, and Chen CS. A modified low-reynolds-number turbulence model applicable to recirculating flow in pipe expansion. Journal of Fluids Engineering, 1995;117 (3): 417-423.

[30] Menter FR. Two-equation eddy-viscosity turbulence models for engineering applications. AIAA Journal, 1994;32: 1598-1605.

[31] Van Hooff, T and Blocken, B and Defraeye, T and Carmeliet, Jand van Heijst, G. PIV measurements of a plane wall jet in a confined space at transitional slot Reynolds numbers. Experiments in Fluids, 2012;pages no-no; doi: 10.1007/s00348-012-1305-5

[32] Van Hooff, T and Blocken, B and Defraeye, T and Carmeliet, J and van Heijst, G. PIV measurements and analysis of transitional flow in a reduced-scale model: Ventilation by a free plane jet with coanda effect. Building and Environment, 2012;56 (0): 301-313;doi: $\underline{10.1016 / \text { j.buildenv.2012.03.020. }}$.

[33] Dewan A. Tackling Turbulent Flows in Engineering. 1st edition. New Delhi: Springer; 
Accepted Manuscript

2011.

[34] ANSYS Fluent Inc., 14.0, FLUENT User's Guide, PA, Canonsburg.

[35] Wolfshtein M. The Velocity and Temperature Distribution of One-Dimensional Flow

With Turbulence Augmentation and Pressure Gradient. Int.J. Heat Mass Transfer, 1969;12: $301-318$.

[36] Li Y, Nielsen Peter V. CFD and Ventilation Research. Indoor Air, 2011; Vol 21( 6): $442-453$. 
Accepted Manuscript

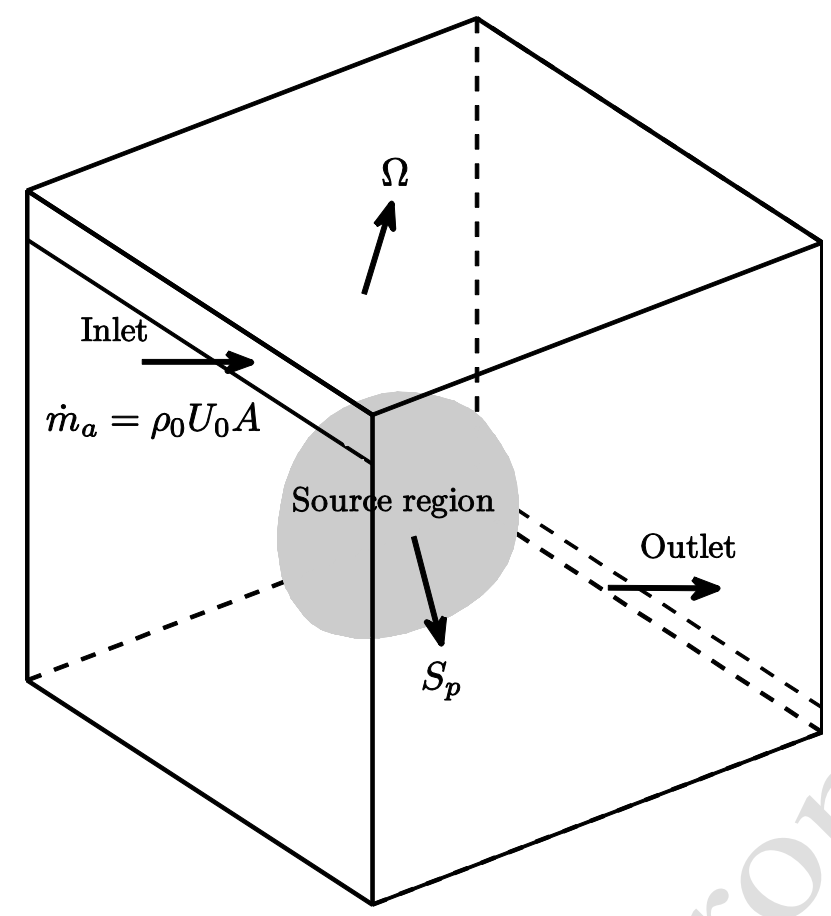

Figure 1: Outline of a simple indoor-ventilation case 


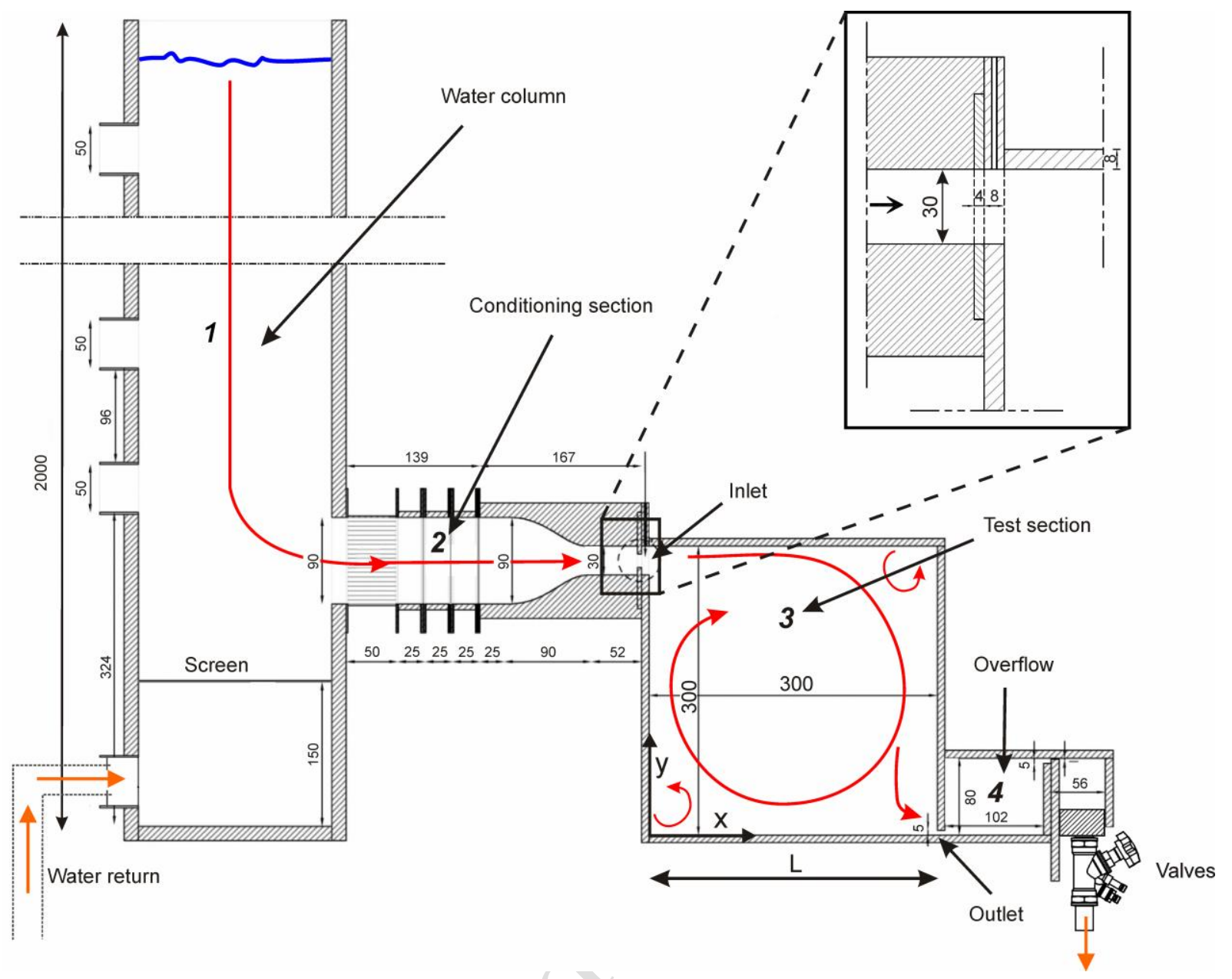

Figure 2: Reduced-scale setup used for the flow visualizations and PIV measurements. This figure shows the water column (1), the flow conditioning section in front of the inlet (2), the test section (3), the overflow (4), and the valves that are placed in a block after the overflow (Dimensions in mm). Figure courtesy of B. Blocken and T. van Hoof [31]. 
Accepted Manuscript

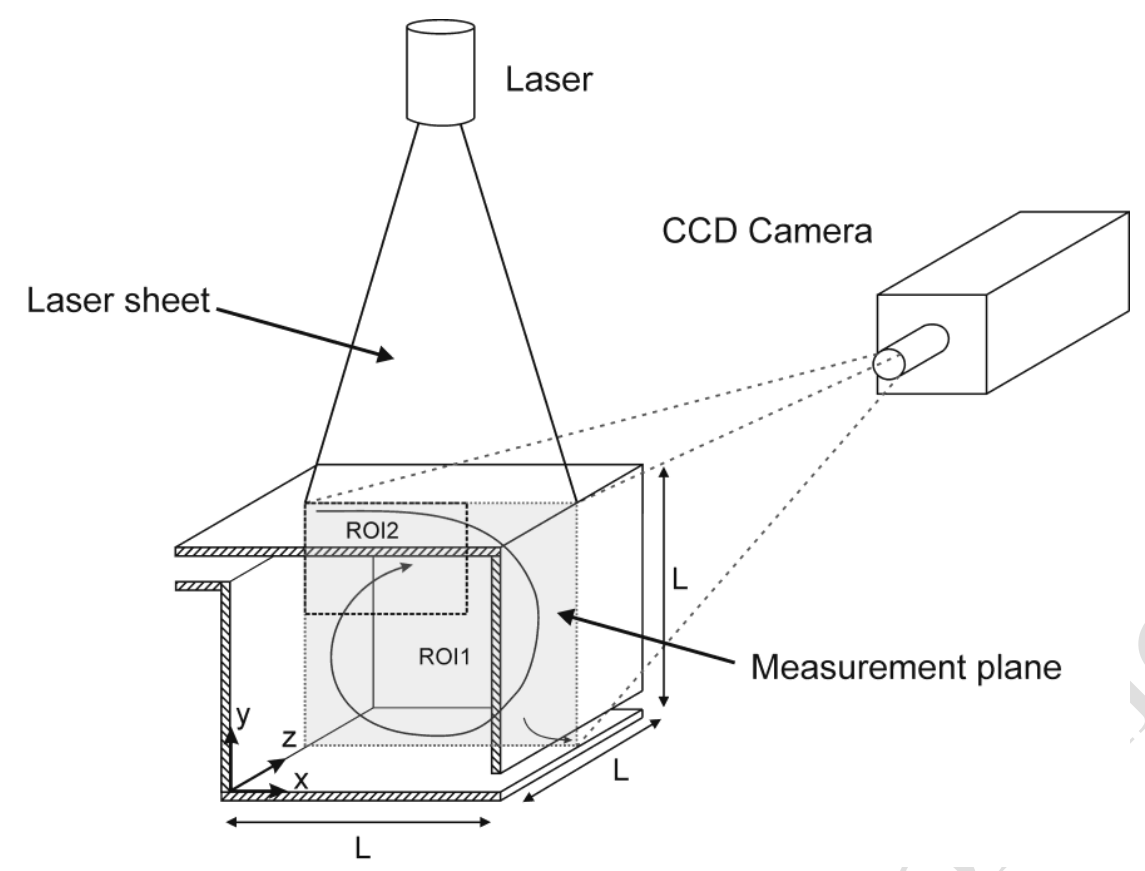

Figure 3: PIV measurement set-up; the laser head was positioned above the test section using translation stage. ROI1 indicates the region of interest (L x L) for the first measurement set, ROI2 indicates the region of interest of $0.6 \mathrm{~L} \times 0.4 \mathrm{~L}(\mathrm{~W} \times \mathrm{H})$ for the second set. Figure courtesy of B. Blocken and T. van Hoof [32]. 


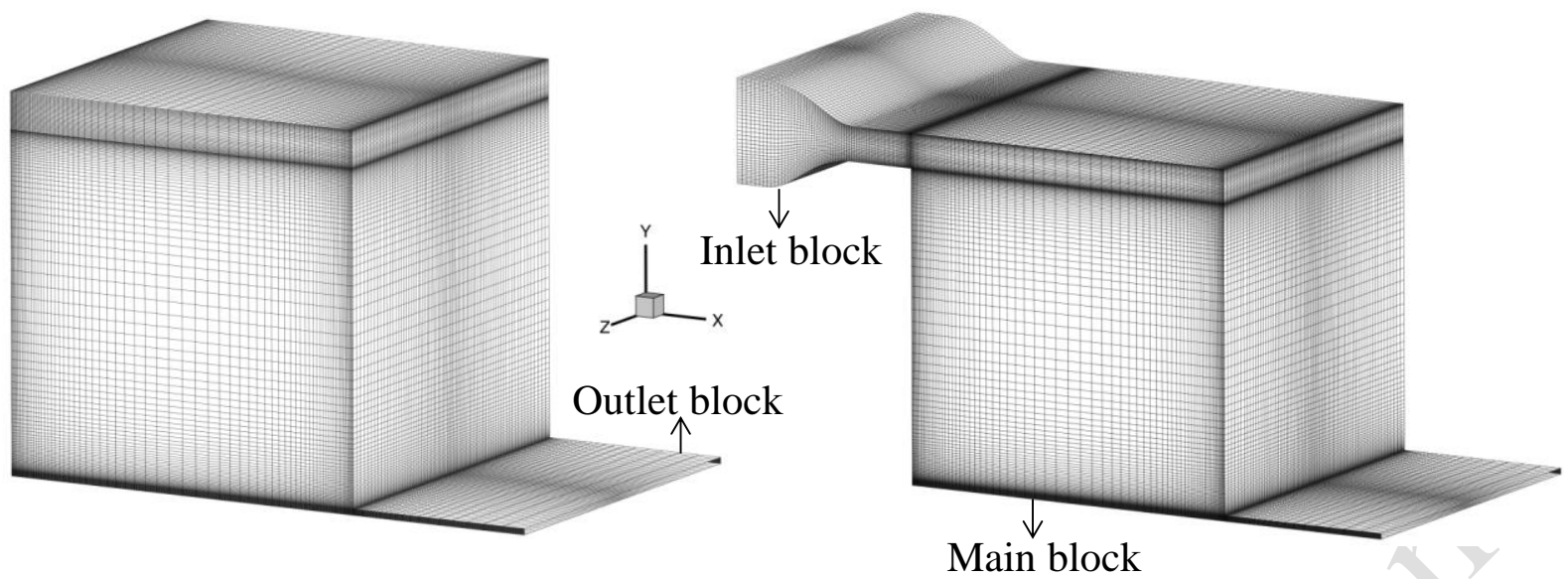

Figure 4: Computational set up of the indoor-ventilation test case. (a): without inlet block; (b): with inlet block 

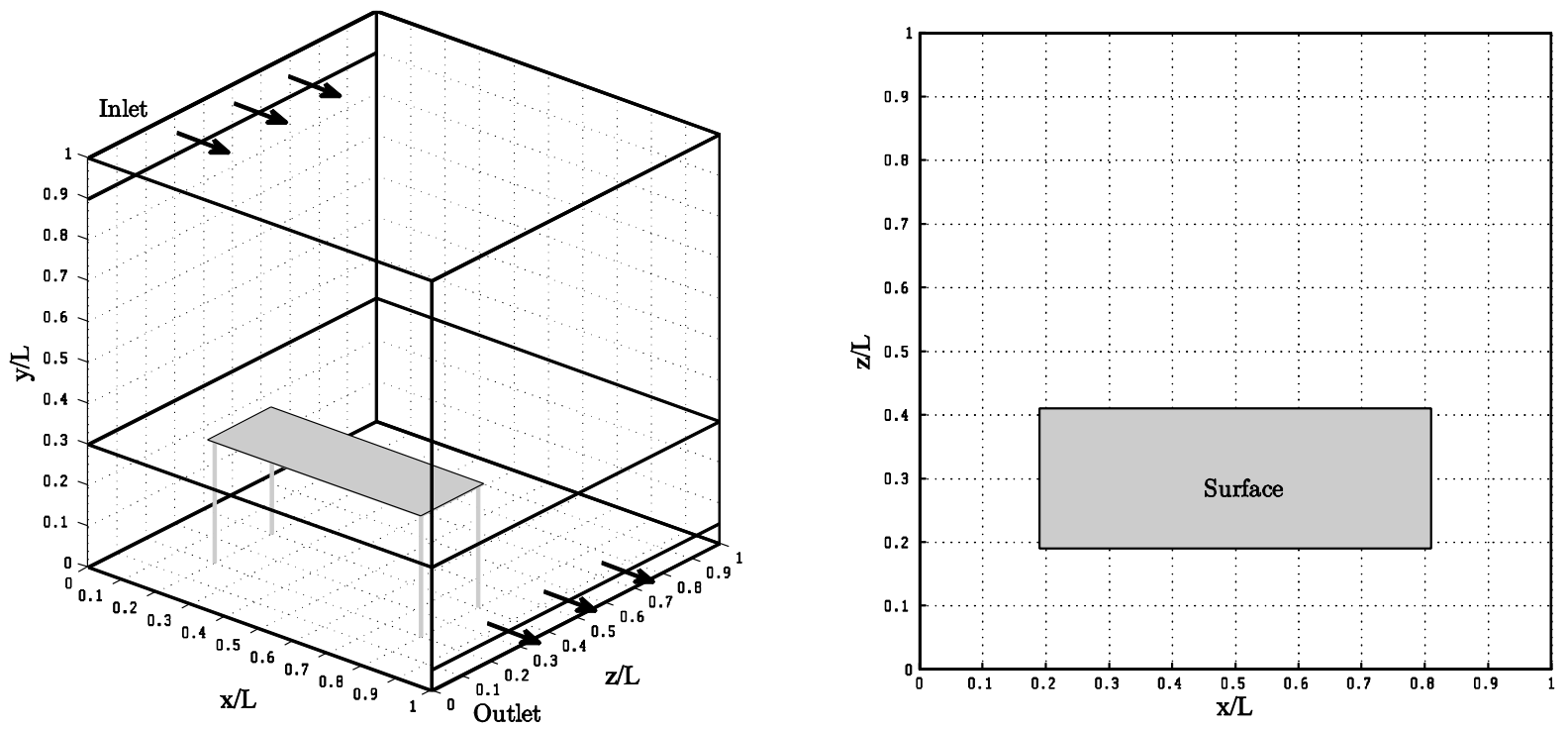

Figure 5: Schematic view of uniformly distributed pollutant surface source, located at the plane with height of $\mathrm{y}=0.3 \mathrm{~L}$ 

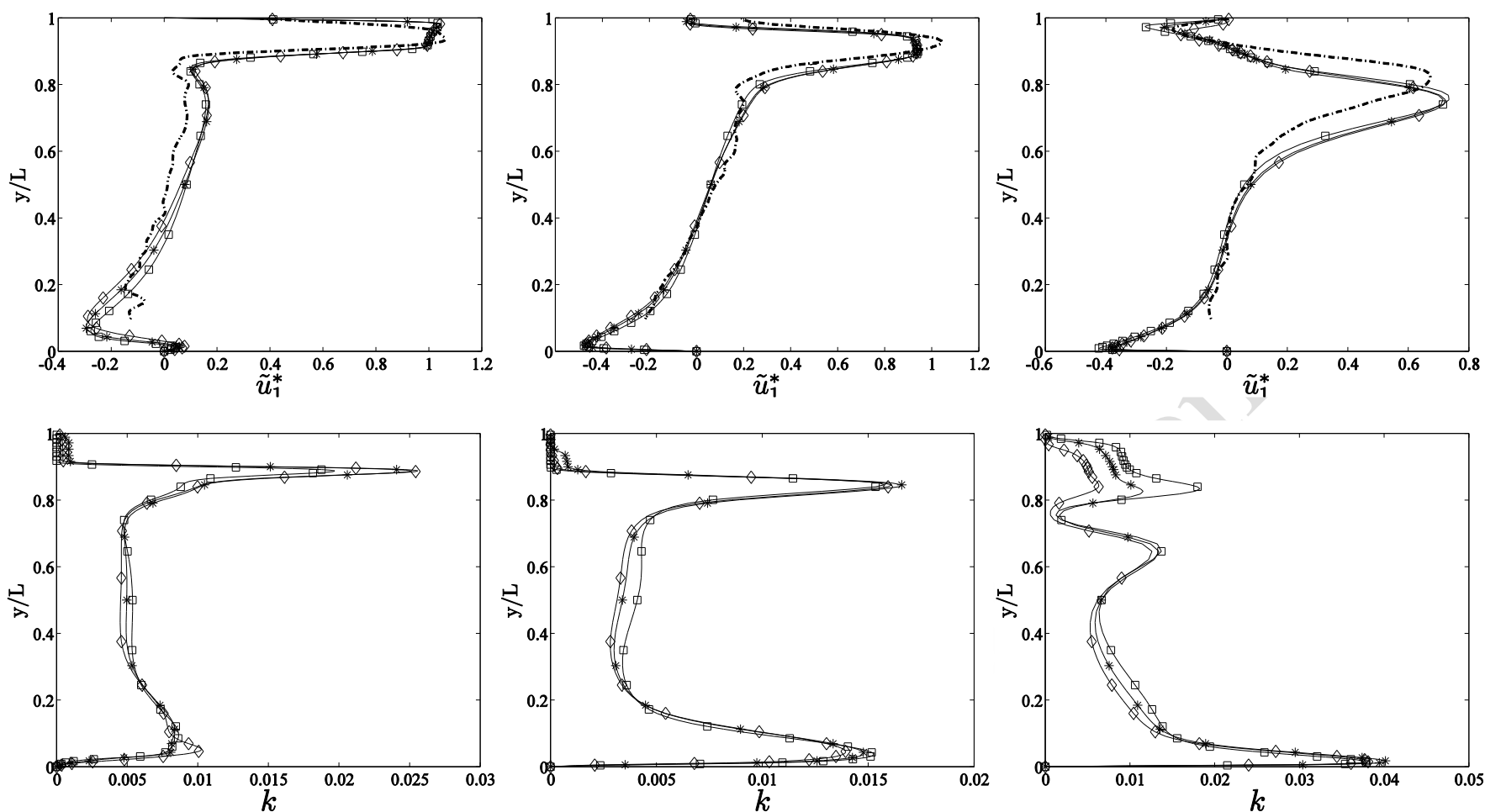

Figure 6: Comparison of x-velocity component (top), and turbulent kinetic energy (bottom) as obtained from experiments and low-Re $k-\varepsilon$ RANS simulations with different inlet turbulent length scales. (left) along $(\mathrm{x}, \mathrm{z})=(0.2 \mathrm{~L}, 0.5 \mathrm{~L}) ;($ middle) along $(\mathrm{x}, \mathrm{z})=(0.5 \mathrm{~L}, 0.5 \mathrm{~L})$; and (right) along $(\mathrm{x}, \mathrm{z})=(0.8 \mathrm{~L}, 0.5 \mathrm{~L})$. Symbols: $\left({ }^{*}\right): \mathrm{L}_{\mathrm{t}}=1 \times 10^{-2} ;(\diamond): \mathrm{L}_{\mathrm{t}}=1 \times 10^{-3}$; and $(\square): \mathrm{L}_{\mathrm{t}}=1 \times 10^{-4}$. Dashed line: experimental results 


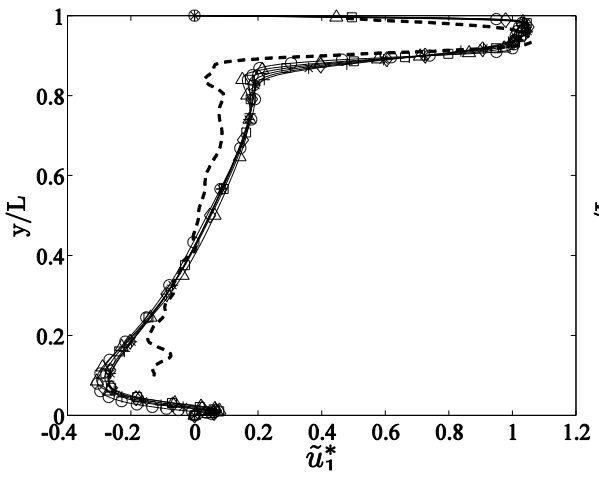

(a)

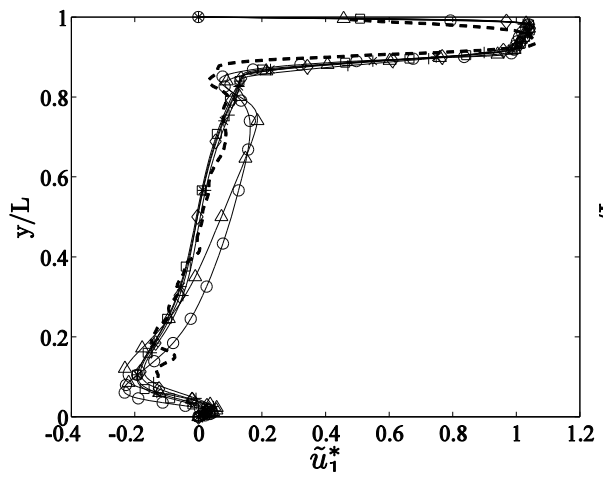

(d)

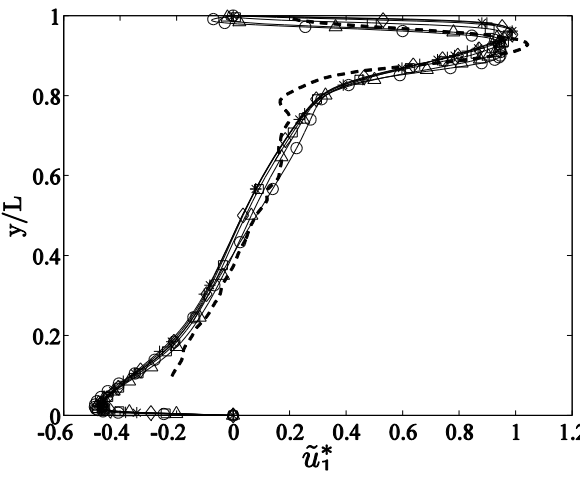

(b)

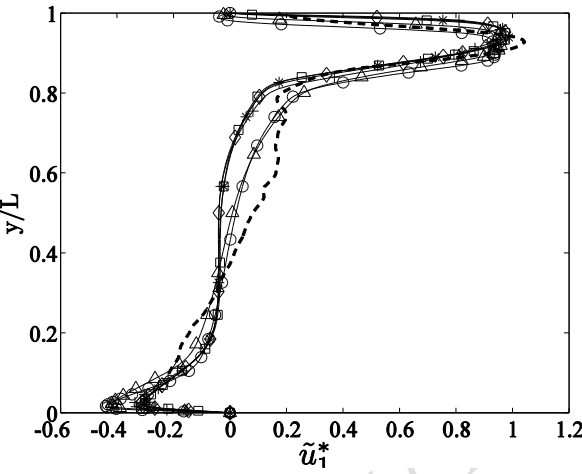

(e)

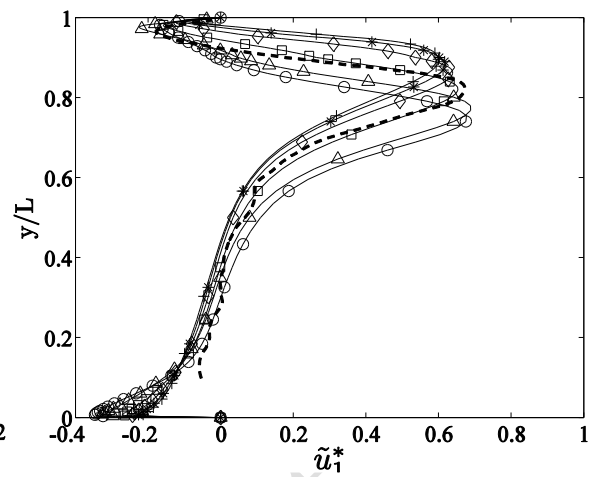

(c)

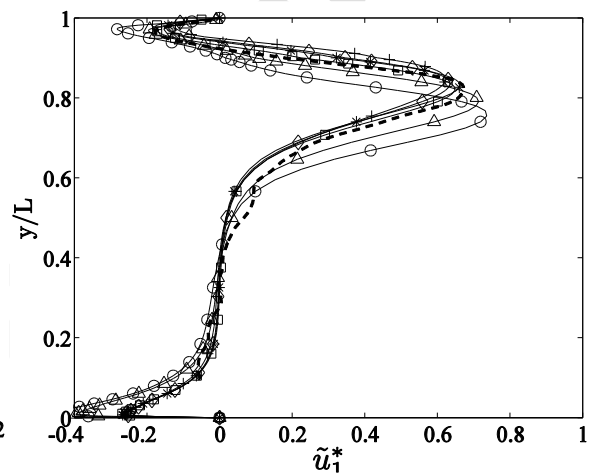

(f)

Figure 7: Comparison of non-dimensional horizontal velocity $\tilde{u}_{1}^{*}$ as obtained from experimental and numerical results. $(\mathrm{a}, \mathrm{b}, \mathrm{c})$ : low-Re $k-\varepsilon$ model; $(\mathrm{d}, \mathrm{e}, \mathrm{f})$ : SST $k-\omega$ model. Simulations are performed with different inlet turbulent intensities: symbols represent $(0): 5 \%$; $(\Delta): 10 \%$; $(\square): 15 \% ;(\diamond): 20 \% ;(*): 25 \% ;(+): 30 \%$; (dashed line): experiment. Results are shown $(\mathrm{a}, \mathrm{d})$ along $(\mathrm{x}, \mathrm{z})=(0.2 \mathrm{~L}, 0.5 \mathrm{~L}) ;(\mathrm{b}, \mathrm{e})$ along $(\mathrm{x}, \mathrm{z})=(0.5 \mathrm{~L}, 0.5 \mathrm{~L})$, and $(\mathrm{c}, \mathrm{f})$ along $(\mathrm{x}, \mathrm{z})=(0.8 \mathrm{~L}, 0.5 \mathrm{~L})$ 


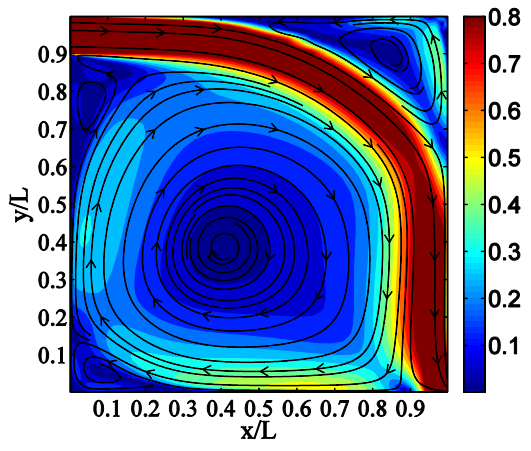

(a)

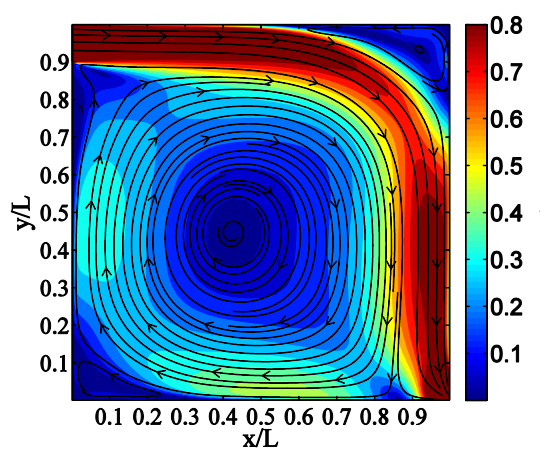

(d)

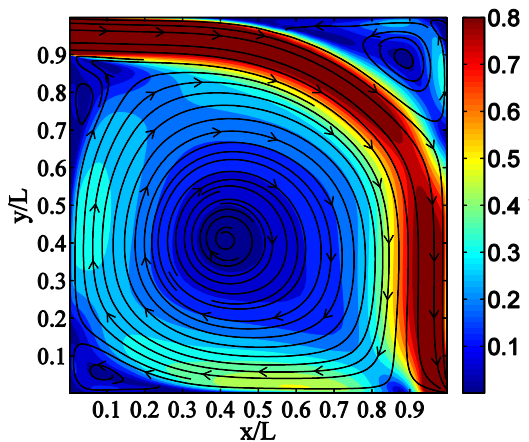

(b)

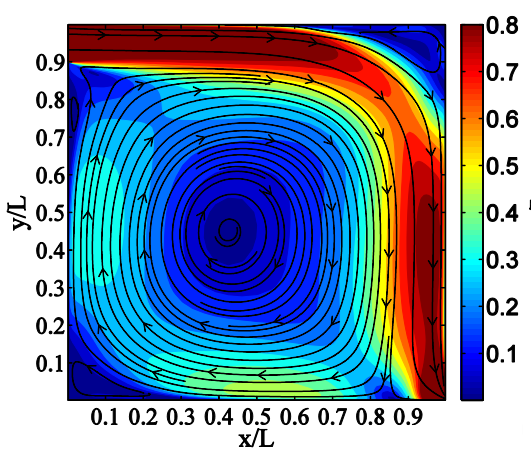

(e)

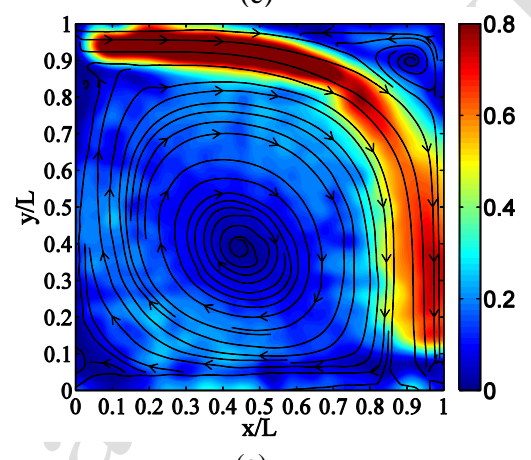

(g)

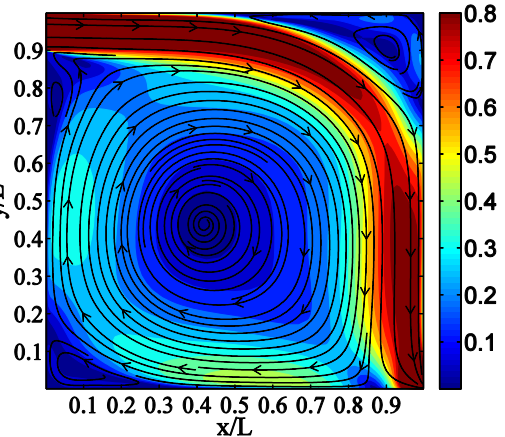

(c)

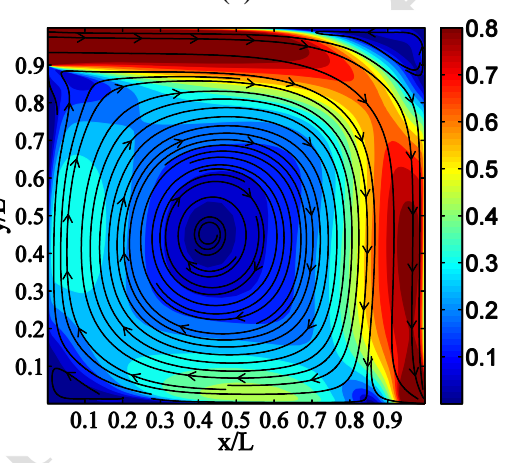

(f)

Figure 8: Streamlines and velocity magnitude (in color) at $\mathrm{xy}$-plane $(\mathrm{z}=0.5 \mathrm{~L})$ for different inlet turbulent intensities (a-f) with low-Re $k$ - $\varepsilon$ model, respectively corresponding to $5 \%, 10 \%$, $15 \%, 20 \%, 25 \%, 30 \%$; (g): experimental results obtained by PIV measurements. 


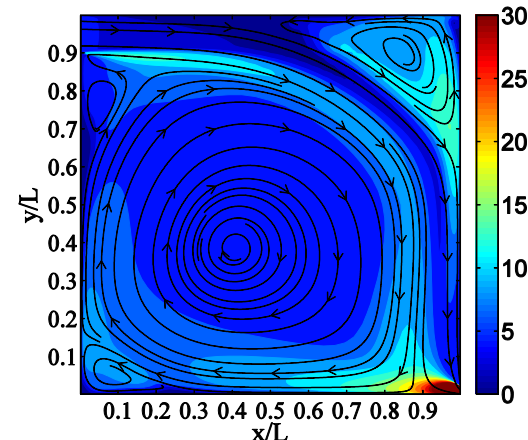

(a)

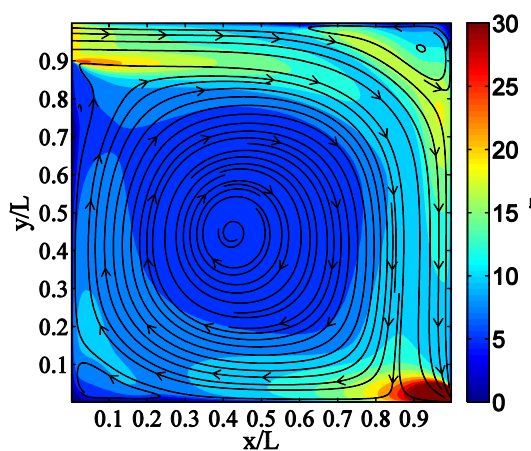

(d)

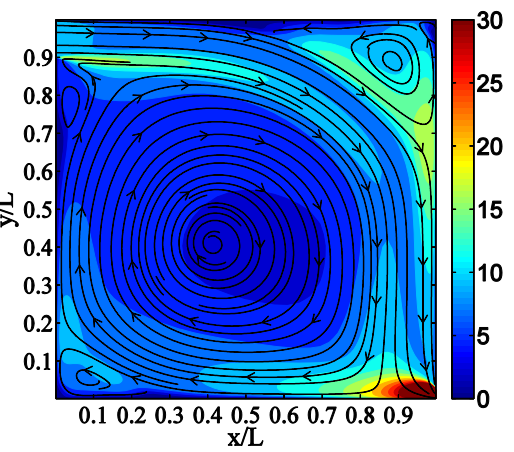

(b)

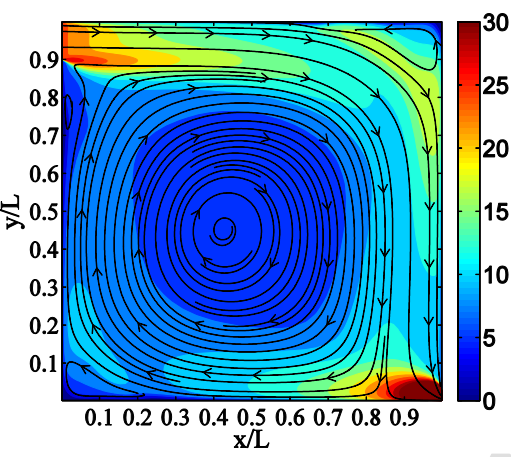

(e)

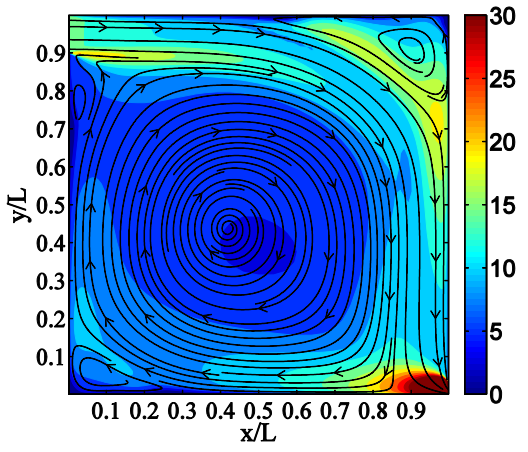

(c)

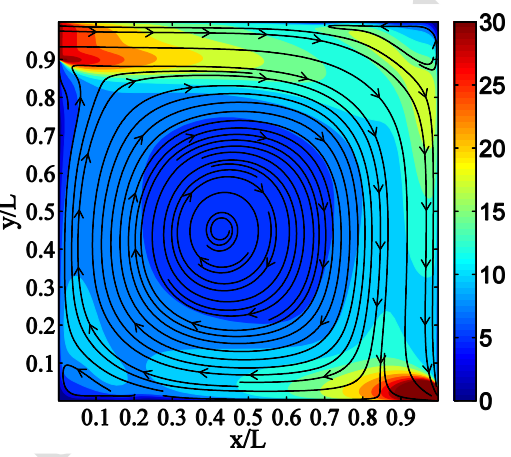

(f)

Figure 9: Streamlines and turbulence intensity (in color) at $x y-p l a n e(z=0.5 \mathrm{~L})$ for different inlet turbulent intensities (a-f) low-Re $k-\varepsilon$ model, respectively corresponding to $5 \%, 10 \%$, $15 \%, 20 \%, 25 \%, 30 \%$ 


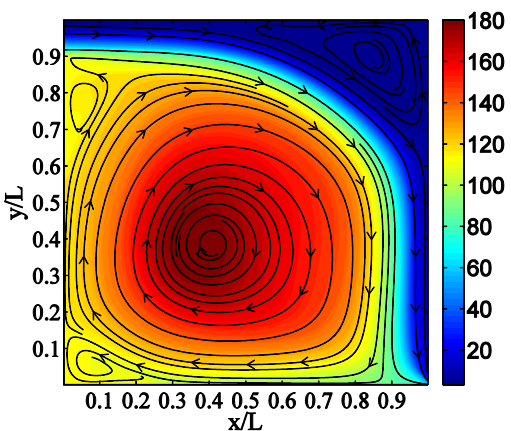

(a)

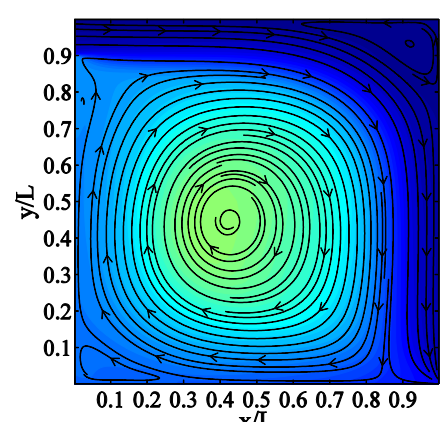

(d)

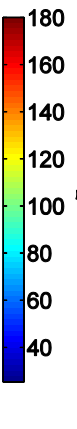

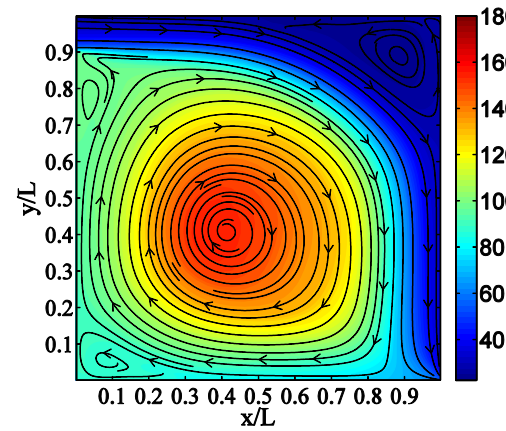

(b)

180
160
140
120
100
80
60
40

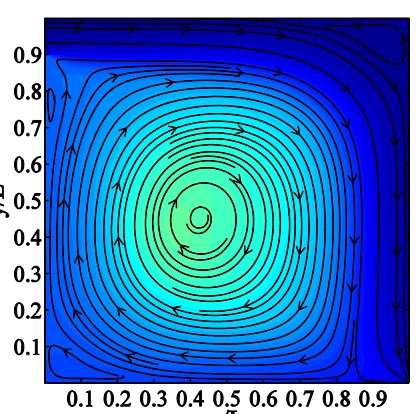

(e)

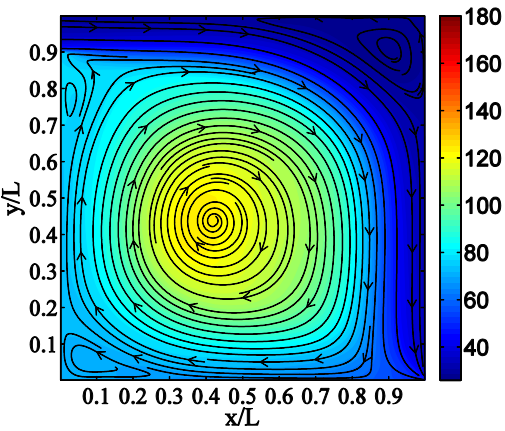

(c)

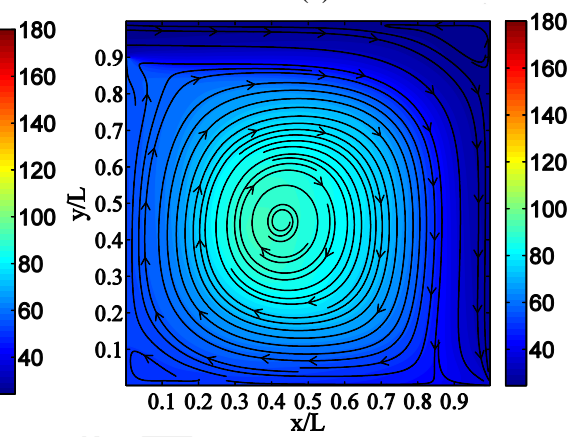

(f)

Figure 10: Streamlines and concentration magnitude (in color) at $x y-p l a n e ~(z=0.5 \mathrm{~L})$ for different inlet turbulent intensities (a-f) with low-Re $k$ - $\varepsilon$ model, respectively corresponding to $5 \%, 10 \%, 15 \%, 20 \%, 25 \%, 30 \%$ 
Accepted Manuscript

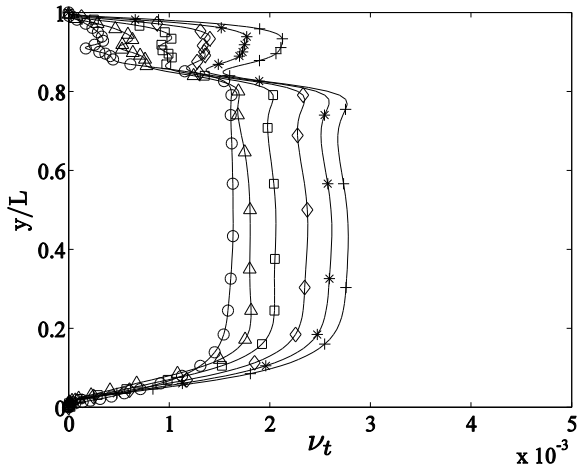

(a)

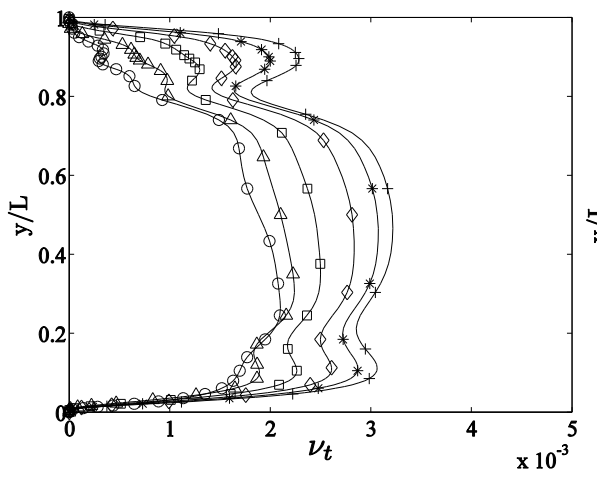

(b)

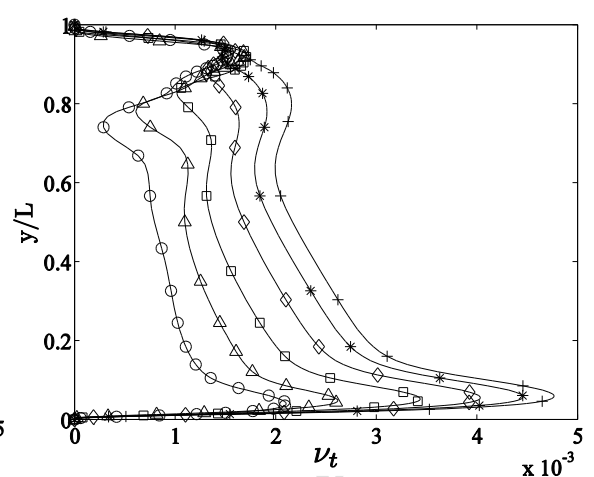

(c)

Figure 11: Comparison of turbulent viscosity profiles for different inlet turbulent intensities obtained using the low-Re k- $\varepsilon$ model (simulations use the same pollutant source rate). (a) along $(\mathrm{x}, \mathrm{z})=(0.2 \mathrm{~L}, 0.5 \mathrm{~L})$; (b) along $(\mathrm{x}, \mathrm{z})=(0.5 \mathrm{~L}, 0.5 \mathrm{~L})$; and (c) along $(\mathrm{x}, \mathrm{z})=(0.8 \mathrm{~L}, 0.5 \mathrm{~L})$. Inlet intensities correspond with $(\circ): 5 \% ;(\Delta): 10 \% ;(\square): 15 \% ;(\diamond): 20 \% ;(*): 25 \%$; and $(+): 30 \%$ 
Accepted Manuscript

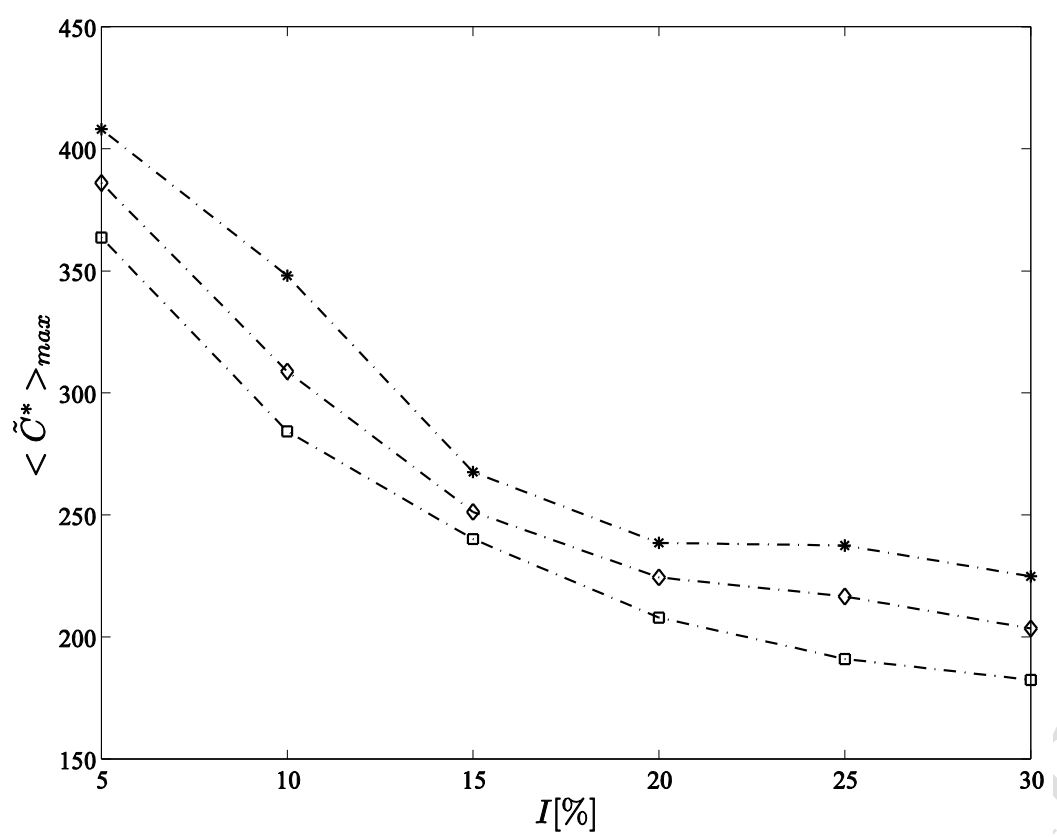

Figure 12: Maximum of local-averaged concentration (averaged over a local volume with size $\left.(0.1 \mathrm{~L})^{3}\right)$ as function of different inlet turbulent intensities for three inlet turbulent length scales using the low-Re k- $\varepsilon$ model. Symbols- (口): $\mathrm{L}_{\mathrm{t}}=1 \times 10^{-2} \mathrm{~L} ;(\diamond): \mathrm{L}_{\mathrm{t}}=5 \times 10^{-3} \mathrm{~L}$; and $(*)$ : $\mathrm{L}_{\mathrm{t}}$ $=3 \times 10^{-4} \mathrm{~L}$ 


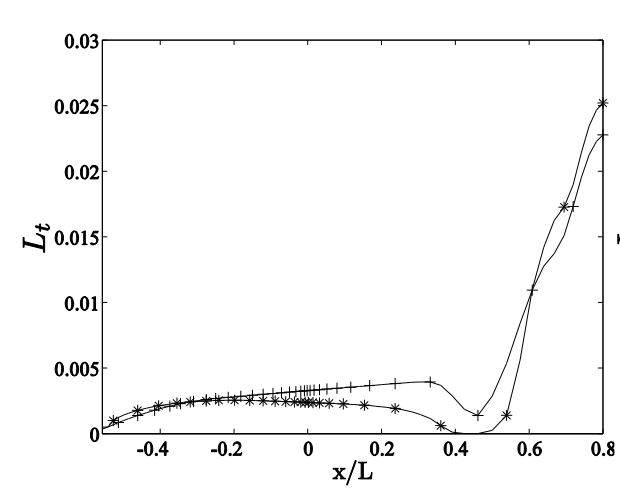

(a)

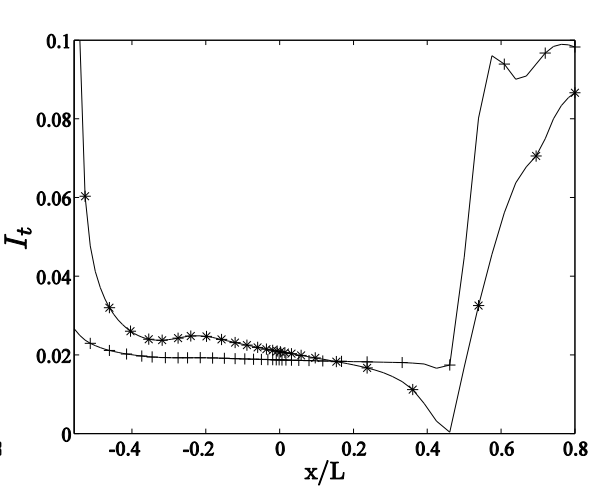

(b)

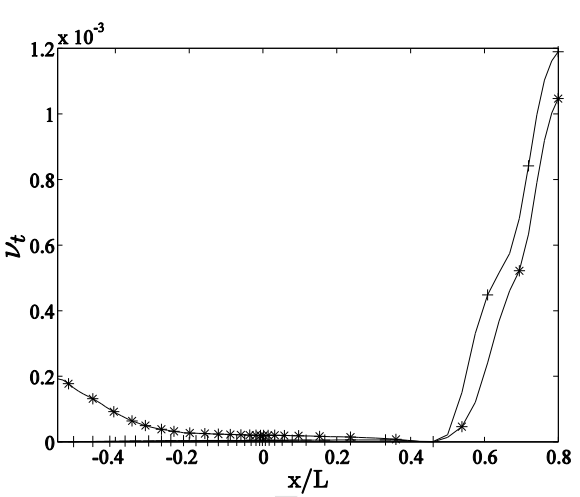

(c)

Figure 13: Evolution of turbulent parameters along the centerline of the upstream contraction and inflow jet, with $(\mathrm{a}, \mathrm{b}, \mathrm{c})$ respectively corresponding to turbulent length scale $L_{t}$, turbulent intensity $I_{t}$, turbulent viscosity $v_{t}$. Symbols - $\left(^{*}\right)$ : low-Re $k-\varepsilon$ model and $(+)$ : SST k- $\omega$ model 

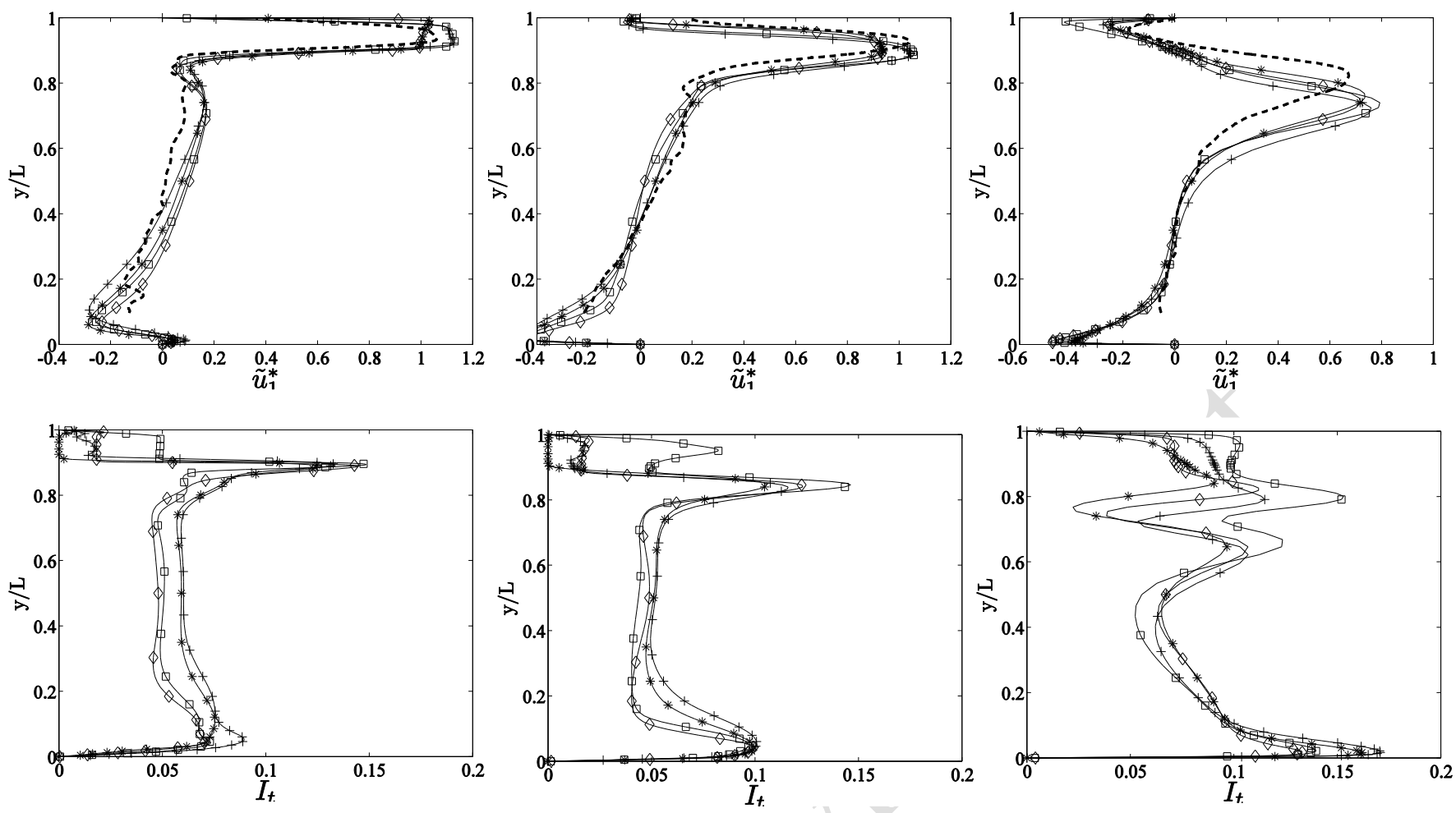

Figure 14: Comparison of non-dimensional horizontal velocity $\tilde{u}_{1}^{*}$ (top) and turbulent intensity $I_{t}$ (bottom) as obtained from experimental and numerical results. (left) along $(\mathrm{x}, \mathrm{z})=(0.2 \mathrm{~L}, 0.5 \mathrm{~L}) ;($ middle $)$ along $(\mathrm{x}, \mathrm{z})=(0.5 \mathrm{~L}, 0.5 \mathrm{~L})$; and (right) along $(\mathrm{x}, \mathrm{z})=(0.8 \mathrm{~L}, 0.5 \mathrm{~L})$. Symbols-(dashed line): experiment, $(+, *)$ : low-Re k- $\varepsilon$ model and $(\square, \diamond)$ : SST k- $\omega$ model; $(+, \square)$ : with upstream inlet geometry and $(*, \diamond)$ : without upstream inlet geometry. Results are shown (a) along $\quad(\mathrm{x}, \mathrm{z})=(0.2 \mathrm{~L}, 0.5 \mathrm{~L}) ; \quad$ (b) along $\quad(\mathrm{x}, \mathrm{z})=(0.5 \mathrm{~L}, 0.5 \mathrm{~L})$, and (c) along $(\mathrm{x}, \mathrm{z})=(0.8 \mathrm{~L}, 0.5 \mathrm{~L})$ 